\title{
ANALISIS DAN PERENCANAAN KONSEP STRATEGI CONTENT MANAGEMENT CYBERWOMAN PADA SITUS PORTAL CBN.NET.ID
}

\author{
Suryadiputra Liawatimena ${ }^{1}$
}

\begin{abstract}
Article discusses how the CyberWoman management strategy on CBN portal site to serve many information, service, and recovery concept that will be used for its better growing. The article purposes are to know whether the content management strategy of portal site applied by CBN, especially for CyberWoman, has been running well or not and also give a recovery concept in the future. The conclusion indicates that the CBN have opportunity and strength that can be used and the CBN portal site is in the state of growing. Therefore, the applied strategy is an aggressive growing policy strategy and concentration strategy through horizontal integration.
\end{abstract}

Keywords: strategic concept, content management, site, portal

\section{ABSTRAK}

Artikel membahas strategi manajemen CyberWoman pada situs portal CBN dalam menyajikan beragam informasi, layanan, dan konsep perbaikan yang akan digunakan guna perkembangan CyberWoman ke arah yang lebih baik. Tujuan artikel adalah mengetahui apakah strategi manajemen content situs portal yang diterapkan oleh CBN, terutama untuk CyberWoman, telah berjalan dengan baik atau belum serta memberikan konsep perbaikan di masa yang akan datang. Simpulan yang diperoleh adalah CBN memiliki peluang dan kekuatan yang dapat dimanfaatkan dan situs portal CBN berada dalam pertumbuhan. Untuk itu, strategi yang harus diterapkan adalah strategi kebijakan pertumbuhan yang agresif dan strategi konsentrasi melalui integrasi horizontal.

Kata kunci: konsep strategi, content management, situs, portal

\footnotetext{
${ }^{1}$ Jurusan Sistem Komputer, Fakultas Ilmu Komputer, UBiNus, Jl. K.H. Syahdan No. 9, Kemanggisan/Palmerah, Jakarta Barat 11480, suryadi@binus.ac.id
} 


\section{PENDAHULUAN}

PT Cyberindo Aditama (CBN) adalah salah satu perusahaan penyedia layanan internet (internet service provider) yang berkembang di Indonesia. Dengan adanya layanan internet dari CBN, para pengguna internet dapat terhubung dengan siapa pun di belahan dunia manapun melalui internet. Di samping itu, PT Cyberindo Aditama (CBN) yang berkantor di gedung Manggala Wanabakti ini juga menyediakan situs portal guna memenuhi kebutuhan akan informasi bagi para pelanggannya, termasuk pengunjung yang bersifat non-pelanggan. Situs portal CBN www.cbn.net.id dapat diakses oleh siapa saja. Ada 10 (sepuluh) content yang terbagi dalam situs portal ini. Karena PT Cyberindo Aditama (CBN) memberikan perhatian khusus pada keberadaan wanita, dalam situs portal www.cbn.net.id juga disediakan content situs portal yang dikhususkan untuk para wanita Indonesia, yaitu CyberWoman. Pengunjung yang sifatnya pelanggan maupun nonpelanggan juga dapat langsung mengakses content CyberWoman dengan cara masuk ke http://cyberwoman.cbn.net.id.

Topik ini diangkat karena dirasa content situs portal wanita yang selengkap content CyberWoman masih sangat minim. Akan tetapi, situs portal www.cbn.net.id yang bernaung di bawah PT Cyberindo Aditama telah menyediakan content situs portal untuk wanita dengan cukup baik, menarik dan berkualitas, walaupun masih ada beberapa kelemahan yang akan dicarikan solusi konsep perbaikannya melalui penyebaran kuisioner kepada sejumlah responden wanita pengguna content CyberWoman. Adapun content CyberWoman dibagi lagi menjadi 12 (dua belas) sub content, yaitu fashion, beauty, health, career, cooking, mother and baby, love, batita, celebs and kids, smart woman, your tips, serta forum. Penulis mengharapkan dengan konsep perbaikan yang diberikan dapat semakin menyempurnakan content CyberWoman sebagai content situs portal wanita terbaik di Indonesia.

Permasalahan yang akan diteliti dalam penelitian ini adalah Bagaimana strategi manajemen content CyberWoman pada situs portal http://cyberwoman.cbn.net.id? Bagaimana perencanaan konsep perbaikan untuk content CyberWoman pada situs portal http://cyberwoman.cbn.net.id? Tujuan penelitian adalah untuk mengetahui seberapa jauh PT Cyberindo Aditama dalam menyajikan content CyberWoman dalam rangka memenuhi kebutuhan para pelanggan dan penggunanya; Untuk menyumbangkan konsep perbaikan demi penyempurnaan content CyberWoman pada situs portal http://cyberwoman.cbn.net.id di masa yang akan datang. Manfaat penelitian adalah sebagai berikut. Pertama, bagi PT Cyberindo Aditama. Hasil penelitian dapat berguna sebagai informasi, masukan, dan sumbang saran bagi PT Cyberindo Aditama dalam menjalankan strategi manajemen content situs portal CBN.NET.ID sehingga dapat meningkatkan mutu pelayanan kepada para pengguna situs portal tersebut. Kedua, bagi masyarakat. Diharapkan hasil penelitian dapat memasyarakatkan e-Business di Indonesia sehingga masyarakat dan negara Indonesia tidak tertinggal dalam kancah persaingan dunia internasional di era globalisasi ini. 


\section{TINJAUAN PUSTAKA}

Berdasarkan pendapat Rangkuti (2003:3), strategi adalah alat untuk mencapai tujuan perusahaan dalam kaitannya dengan tujuan jangka panjang, program tindak lanjut, dan prioritas alokasi sumber daya. Pada prinsipnya strategi dapat dikelompokkan berdasarkan 3 (tiga) tipe strategi (Rangkuti, 2003:6-7). Pertama, Strategi Manajemen. Strategi manajemen meliputi strategi yang dapat dilakukan oleh manajemen dengan orientasi pengembangan strategi secara makro, misalnya strategi pengembangan produk, strategi penerapan harga, strategi akuisisi, strategi pengembangan pasar, strategi mengenai keuangan, dan sebagainya. Kedua, Strategi Investasi. Strategi itu merupakan kegiatan yang berorientasi pada investasi. Misalnya, apakah perusahaan ingin melakukan strategi pertumbuhan yang agresif atau berusaha mengadakan penetrasi pasar, strategi bertahan, strategi pembangunan kembali suatu divisi baru atau strategi divestasi, dan sebagainya. Ketiga, Strategi Bisnis. Strategi bisnis ini sering juga disebut strategi bisnis secara fungsional karena strategi itu berorientasi pada fungsi kegiatan manajemen, misalnya strategi pemasaran, strategi produksi atau operasional, strategi distribusi, strategi organisasi, dan strategi yang berhubungan dengan keuangan.

Menurut Turban (2002:880), e-business adalah definisi dari e-commerce, meliputi intrabisnis, Inter Organizational System (IOS), dan e-commerce. Banyak digunakan untuk menjadi pedoman e-commerce. Berdasarkan pendapat Amor (2004:27), electronic business (e-business) adalah suatu bentuk super dari kasus bisnis yang telah didigitalisasi dan sekarang bekerja di internet. Suatu kategori e-business didefinisikan oleh kasus bisnis dan bukan oleh teknologi yang digunakan untuk mengimplementasikannya. Selama itu, lebih dan lebih banyak lagi tipe bisnis akan dikonversikan dalam bentuk digital. Berbagai bentuk bisnis akan saling terhubung, cepat atau lambat. Teknologi berkembang cukup cepat untuk menjadikan suatu hal yang terlihat tidak mungkin hari ini menjadi mungkin esok hari.

Berdasarkan pendapat Kalakota (2001:87-88), portal sebagai perantara atau penengah yang menawarkan suatu pelayanan yang terkumpul untuk kelompok pengguna yang spesifik. Portal terjadi ketika pemain baru sukses dalam menempatkan diri diantara konsumen dan pemasok. Biasanya, secara ekstrim konsumen yang difokuskan oleh para pemain baru memasuki rantai yang berhubungan dengan ketidakpuasan konsumen secara spesifik dengan sistem saat ini dalam menjalankan bisnis.

Menurut Turban (2002:29), portal adalah pintu gerbang besar dan lewat portal tersebut para karyawan, rekan bisnis, dan masyarakat dapat mengakses informasi perusahaan dan berhubungan serta berkolaborasi sebagaimana yang dibutuhkan. Banyak perusahaan yang bergerak menuju konfigurasi jaringan yang sama. Saat ini, sangat tidak mungkin melakukan bisnis dengan para rekan bisnis tanpa dihubungkan melalui Internet, ekstranet, atau EDI (Extranet Data Interchange). Portal dikembangkan dari mesin pencari dalam suatu usaha untuk melengkapi pintu gerbang yang komprehensif menuju Internet (Turban, 2002:66). 
Berdasarkan pendapat Nakano (2002:191), content adalah hal yang digunakan kembali dan sindikasinya membuka makna baru untuk mengambil inti dari nilai ekonomis tambahan dari aset berharga yang tak dapat dipisahkan, seperti teks, grafik, dan berbagai tipe media. Pada website konvensional, sebuah aset yang eksistensinya dikelilingi dengan halaman HTML. Penggunaan kembali memungkinkan tetapi aset itu perlu dikutip dengan informasi tentang aset itu sendiri, suatu kutipan kadang-kadang ditunjuk sebagai metadata. Kutipan itu harus mengandung informasi dasar, seperti pendeskripsian, pembuatnya dan tanggal pembuatannya, bersama dengan informasi pengindeksan, menggunakan garis penuntun, dan informasi yang berkaitan. Dalam beberapa cara kutipan dari sebuah aset, apakah itu jenis data primitif atau sebaliknya, tidak berbeda dari jenis data yang sebaliknya dari subset metadata. Untuk sebuah kebebasan bergerak kita sendiri, sebuah aset mengandung metadata deskriptif, dapat melayani sebagai aset yang dapat dipercaya. Mungkin, hal itu memperoleh identitasnya sendiri. Kutipan content memerlukan a tag-savvy repository. Content management adalah tata tertib yang mengatur waktu secara akurat, bekerja sama, pengulangan, dan pengembangan yang dapat direproduksi dari properti web (Nakano, 2002:33). Hal itu mengombinasikan mekanisme untuk menyimpan koleksi aset web dengan memproses aktivitas yang sempurna dari manusia dan mesin di dalam organisasi. Content management merespons kombinasi unik masalah yang disikapi oleh pengembangan web.

\section{METODE PENELITIAN}

Metode yang dipergunakan adalah Metode Deskriptif dengan Jenis Penelitian Studi Kasus. Yang dimaksud di sini adalah data yang telah diperoleh dari studi kasus yang diambil, baik secara primer maupun sekunder, diolah dan dianalisis dengan Metode Deskriptif. Definisi operasional dan instrumen pengukuran disajikan dalam Tabel 1.

Tabel 1 Definisi Operasional dan Instrumen Pengukuran

\begin{tabular}{|c|c|}
\hline Variabel Indikator & Sub Indikator \\
\hline Data Pengunjung & $\begin{array}{l}\text { Usia } \\
\text { Pendidikan terakhir } \\
\text { Pekerjaan } \\
\text { Status berlangganan CBN }\end{array}$ \\
\hline $\begin{array}{c}\text { Aktivitas } \\
\text { Pengunjung }\end{array}$ & $\begin{array}{l}\text { Frekuensi menggunakan internet } \\
\text { Frekuensi kunjungan ke CyberWoman }\end{array}$ \\
\hline Kinerja Perusahaan & $\begin{array}{l}\text { Bandwith CBN } \\
\text { Tampilan konten CyberWoman } \\
\text { Skala kunjungan ke sub - sub content yang ada di CyberWoman } \\
\text { Ketertarikan pengunjung terhadap CyberWoman } \\
\text { Tingkat interaktifitas CyberWoman } \\
\text { Manfaat informasi yang diperoleh pengunjung CyberWoman } \\
\text { Kepuasan terhadap informasi dan layanan yang diberikan CyberWoman }\end{array}$ \\
\hline
\end{tabular}


Teknik analisis data yang digunakan oleh penulis dalam melakukan penelitian adalah Analisis SWOT (Strength-Weakness-Opportunity-Threat), Analisis Porter, serta Diagram Cartesius. Sampel untuk Kuesioner menggunakan teknik Non-Probability karena adanya keterbatasan waktu. Skala Likert adalah suatu alat atau metode untuk mengukur sikap, pendapat, dan persepsi responden terhadap suatu objek yang sedang diteliti. Setelah itu, data dikelompokkan dengan teknik pembobotan (rating). Hasil pengumpulan data dengan skala Likert ini diolah lebih lanjut dengan perhitungan dan diposisikan pada Diagram Cartesius.

\section{PEMBAHASAN}

PT Cyberindo Aditama adalah sebuah perusahaan pelopor penyedia jasa internet (Internet Service Provider/ISP) terkemuka yang membawahi situs portal www.cbn.net.id. Data kantor pusat PT Cyberindo Aditama adalah sebagai berikut.

Alamat : Gedung Manggala Wanabakti IV Lantai 6, Jalan Gatot Subroto, Senayan, Jakarta 10270 - Indonesia

Telepon : $021-57994500$, Faksimili : $021-5742481$

e-Mail : info@cbn.net.id

Perusahaan ini didirikan pada tanggal 30 November 1995, dua tahun sebelum krisis moneter Asia yang meruntuhkan banyak ISP di Indonesia. Pada saat itu, CBN hanya mampu memberikan bandwith sebesar 128 Kbps. Namun, saat ini CBN mampu memberikan layanan bandwith sebesar 238 Mbps serta menyediakan lebih dari 4.000 (empat ribu) saluran telepon untuk akses internet dial-up. Tiga aspek legal yang menyertai terbentuknya PT Cyberindo Aditama adalah Article of Incorporation No. 3, pada tanggal 26 April 1995; Putusan Menteri Kehakiman Indonesia No. C2-7599 HT.01.01, pada tahun 1995; Putusan Menteri Pariwisata, Pos \& Telekomunikasi No. 16/PT.102/MPPT-96, pada tanggal 13-3-1996. Ketiga izin tersebut adalah izin yang bersifat prinsip kemudian harus diperbaharui menjadi izin operasional yang bervariasi sesuai dengan kebutuhan operasional perusahaan. Ada juga yang membutuhkan tambahan izin, seperti frekuensi, internet telepon, jaringan akses bagi provider.

\section{Analisis Data Demografis Responden}

Responden yang berpartisipasi dalam pengisian kuisioner berjumlah dua ratus orang dan semuanya wanita (100\%). Hal itu karena content CyberWoman memang khusus ditujukan untuk para wanita. 


\section{Profil Responden Berdasarkan Usia}

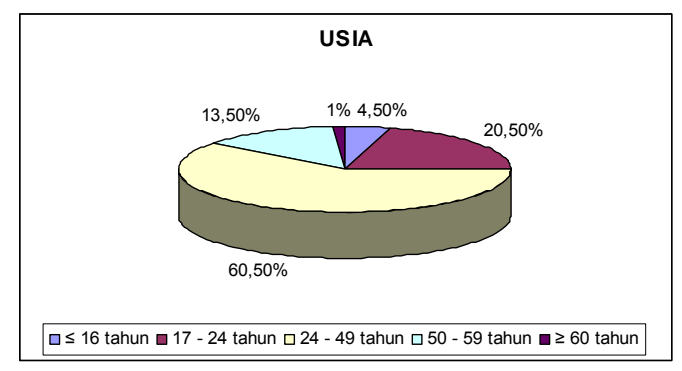

Gambar 1 Profil Responden Berdasarkan Usia

Dari hasil penelitian yang dilakukan, mayoritas wanita pengunjung CyberWoman berusia $24-49$ tahun (60,50\%), lalu diikuti oleh perbedaan yang cukup signifikan, yaitu kelompok usia 17-24 tahun (20,50\%). Di urutan ketiga, kelompok usia 50-59 tahun dengan angka sebesar 13,50\% menyusul. Wanita yang usianya kurang dari 16 tahun hanya sebesar 4,50\%. Dan sisanya 1\% adalah kelompok usia lebih dari 60 tahun. Hasil penelitian tersebut menunjukkan bahwa pengunjung CyberWoman dengan kelompok usia di bawah 16 tahun dan kelompok usia di atas 60 tahun sangat minim. Hal itu mungkin disebabkan oleh segmentasi pasar CyberWoman yang diciptakan oleh CBN memang hanya ditujukan kepada wanita usia kerja (masa produktif) karena lebih dari 50\% responden berusia antara 24 tahun sampai dengan 49 tahun.

\section{Profil Responden Berdasarkan Pendidikan Terakhir}

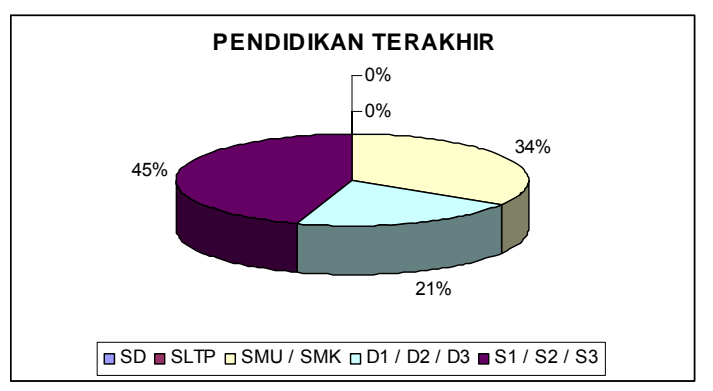

Gambar 2 Profil Responden Berdasarkan Pendidikan Terakhir

Dapat kita lihat dari tabel di atas, walaupun pilihan pendidikan terakhir telah dikategorikan ke dalam 5 (lima) pilihan, namun responden hanya memilih 3 (tiga) diantaranya. Persentase paling besar diperoleh dari responden yang pendidikan terakhirnya Sarjana (S1/S2/S3), yaitu 45\%. Lalu, responden yang pendidikan terakhirnya Sekolah Menengah (SMU/SMK) menyusul dengan poin sebesar 34\%. Yang terakhir angka 21\% untuk responden yang pendidikan terakhirnya Diploma (D1/D2/D3). Dua pilihan yang tidak dipilih oleh responden adalah Sekolah Dasar (SD) dan Sekolah 
Lanjutan Tingkat Pertama (SLTP). Hal itu menunjukkan bahwa penggunaan internet, khususnya CyberWoman di Indonesia, didominasi oleh kalangan terpelajar. Kedua kelompok yang nilainya 0\% tersebut mungkin kurang memperoleh informasi tentang dunia teknologi informasi yang telah berkembang pesat akhir-akhir ini.

\section{Profil Responden Berdasarkan Pekerjaan}

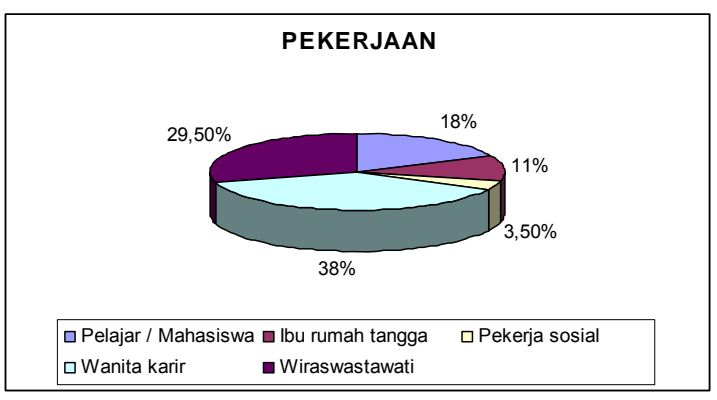

Gambar 3 Profil Responden Berdasarkan Pekerjaan

Jika diurutkan berdasarkan pekerjaan maka posisi pertama adalah wanita karir (38\%), posisi kedua adalah wiraswastawati (29,50\%), posisi ketiga adalah pelajar/ mahasiswa (18\%), posisi keempat adalah ibu rumah tangga (11\%), dan posisi terakhir adalah pekerja sosial (3,50\%). Wanita karir di posisi pertama sesuai dengan data responden berdasarkan usia pada Gambar 1, yaitu usia 24-49 tahun yang menduduki posisi pertama karena kelompok usia tersebut adalah usia kerja.

\section{Profil Responden Berdasarkan Status Pelanggan dan Bukan Pelanggan CBN}

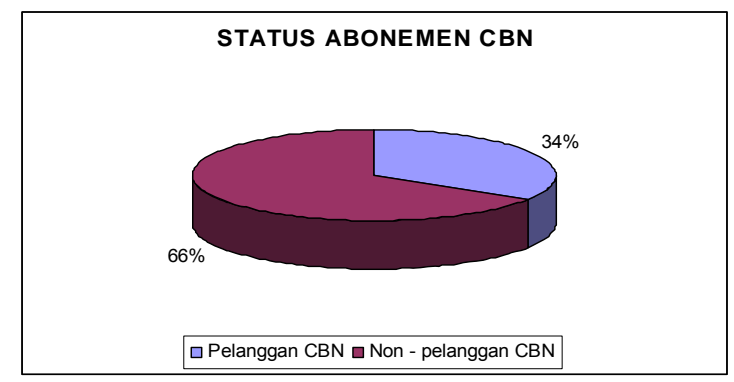

Gambar 4 Profil responden berdasarkan status abonemen CBN

Dari responden yang mengunjungi CyberWoman, tidak semuanya merupakan pelanggan CBN karena portal CBN diperuntukkan kepada siapa saja yang membutuhkan informasi dan layanan lainnya. Mayoritas pengunjung CyberWoman adalah nonpelanggan CBN (66\%) sedangkan pengunjung sekaligus pelanggan CBN berjumlah 34\%. Hal itu memungkinkan CBN untuk lebih meningkatkan promosi di masa yang akan 
datang untuk menarik minat para pengunjung yang sekedar mengunjungi portal CBN dengan tujuan mencari informasi dan layanan lainnya untuk kemudian merubah status mereka menjadi pelanggan CBN.

\section{Analisis Data Aktivitas Responden}

\section{Profil Responden Berdasarkan Frekuensi Penggunaan Internet}

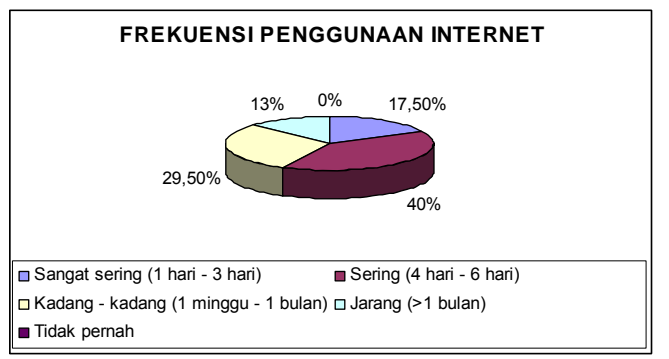

Gambar 5 Profil Responden Berdasarkan Frekuensi Penggunaan Internet

Sebanyak $40 \%$ dari total responden adalah pengguna internet yang sangat aktif, yaitu antara 1 hari sampai dengan 3 hari sekali. Pengguna internet yang frekuensinya hanya kadang- kadang berjumlah 29,50\%. Responden yang sangat sering melakukan aktivitas di internet sebanyak 17,50\%. Hanya 13\% dari responden yang ada lebih dari 1 bulan menggunakan internet dan tidak ada responden yang tidak pernah menggunakan internet. Dapat disimpulkan bahwa para wanita Indonesia telah mengerti internet dengan baik dan dapat menggunakannya dengan baik pula. Untuk itulah CyberWoman sebagai salah satu dari kesepuluh content yang disediakan oleh CBN harus terus melakukan evaluasi dan siap melakukan perbaikan guna menjaring pangsa pasar CBN, khususnya wanita dengan lebih luas lagi.

\section{Profil Responden Berdasarkan Frekuensi Kunjungan ke CyberWoman}

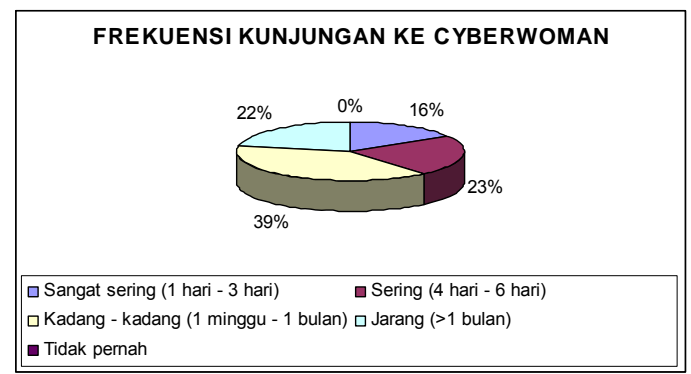

Gambar 6 Profil Responden Berdasarkan Frekuensi Kunjungan ke Cyberwoman 
Terbesar pertama adalah 39\% responden yang melakukan kunjungan (mengakses) CyberWoman hanya kadang-kadang, disusul oleh responden yang sering melakukan akses ke CyberWoman sejumlah 23\%, 22\% adalah persentase untuk responden yang mengakses CyberWoman lebih dari sebulan sekali (jarang). Dan yang terakhir adalah 16\% untuk responden yang sangat sering mengakses CyberWoman. Tidak ada responden yang tidak pernah mengakses CyberWoman.

\section{Analsis Kesesuaian Kinerja Perusahaan dan Tingkat Harapan Pengunjung}

\section{Analisis Kesesuaian Kinerja Situs Portal dan Tingkat Harapan Pengunjung terhadap Tampilan CyberWoman}

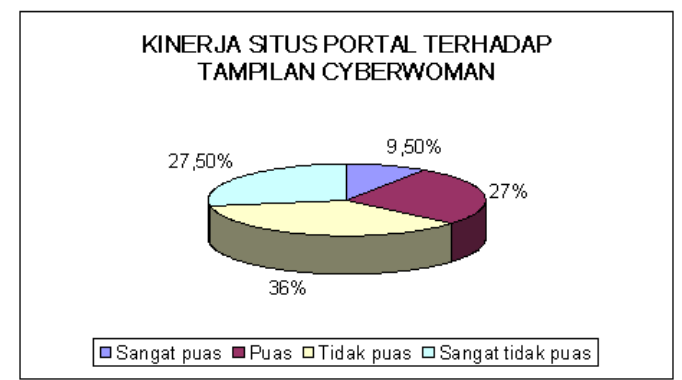

Gambar 7 Kinerja Situs Portal terhadap Tampilan Cyberwoman

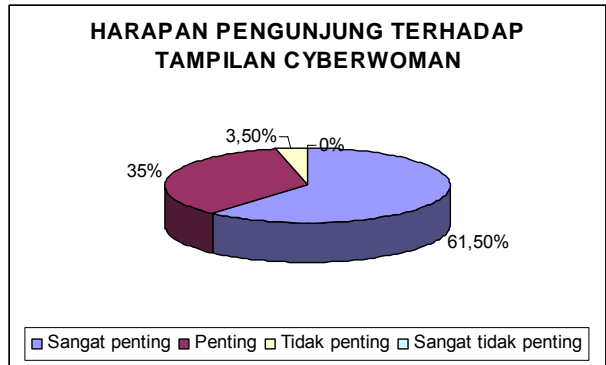

Gambar 8 Harapan Pengunjung terhadap Tampilan Cyberwoman

Dari Gambar 7 dapat dilihat bahwa 36\% responden tidak puas dengan tampilan CyberWoman, sangat tidak puas sebesar 27,50\%, kemudian responden yang menyatakan puas sebesar 27\%. Di urutan terakhir yang menyatakan sangat puas ada 9,5\%. Dari Gambar 8 dapat disimpulkan bahwa lebih dari setengah jumlah responden mengatakan bahwa tampilan sangat penting, yaitu sebesar $61,50 \%$, penting sebesar $35 \%$, tidak penting (3,50\%), dan $0 \%$ untuk pilihan sangat tidak penting. 


\section{Analisis Kesesuaian Kinerja Situs Portal dan Tingkat Harapan Pengunjung terhadap Kecepatan Bandwith CBN.NET.ID}

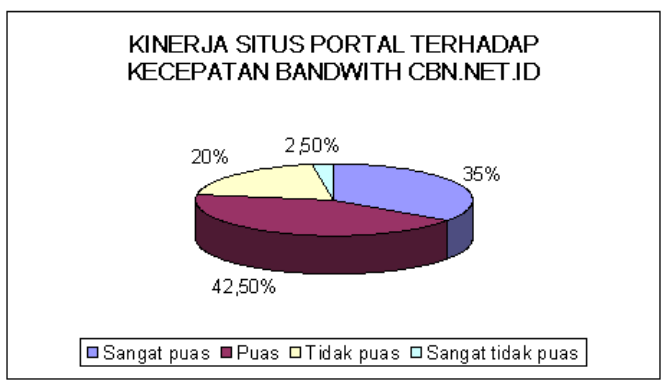

Gambar 9 Kinerja Situs Portal terhadap Bandwith CBN.NET.ID

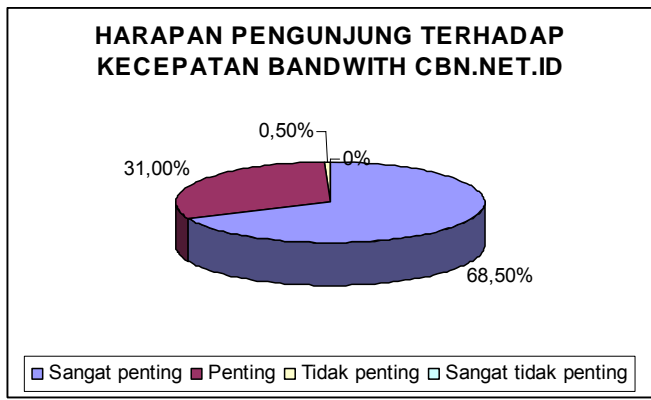

Gambar 10 Harapan Pengunjung terhadap Bandwith CBN.NET.ID

Gambar 9 menunjukkan bahwa 42,50\% dari total responden telah puas dengan kecepatan bandwith CBN, 35\% bahkan mengatakan sangat puas. Minoritas responden sebesar tidak puas $20 \%$ dan sangat tidak puas sebesar 2,50\%. Harapan responden yang dapat dilihat dari Gambar 10 mengatakan bahwa kecepatan bandwith CBN sangat penting (68,50\%), penting (31\%), tidak penting, dan sangat tidak penting $(0 \%)$.

Analisis Kesesuaian Kinerja Situs Portal dan Tingkat Harapan Pengunjung terhadap Tingkat Keinteraktifan CyberWoman

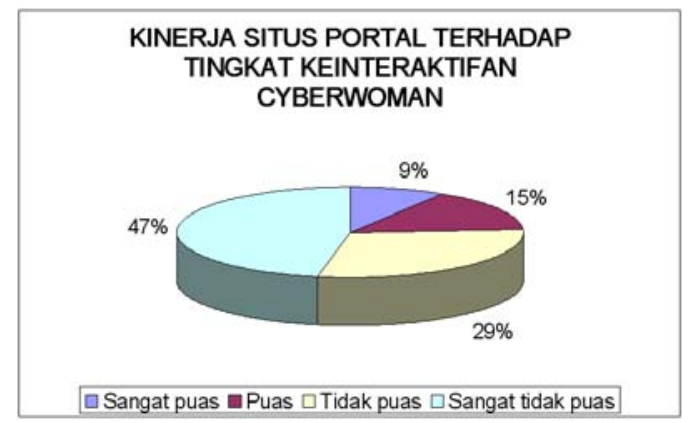

Gambar 11 Kinerja Situs Portal terhadap Tingkat Keinteraktifan Cyberwoman 


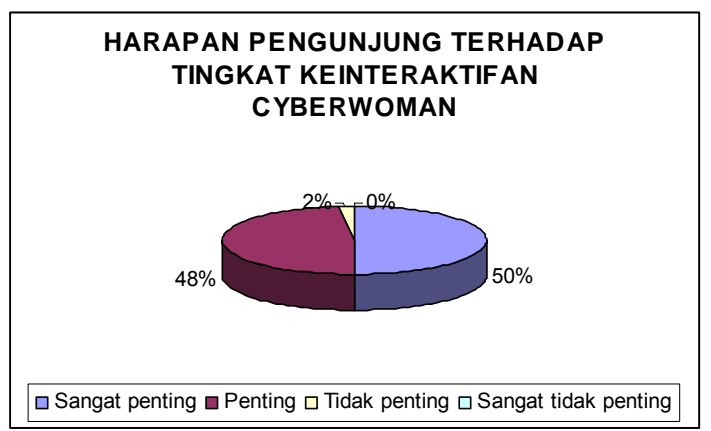

Gambar 12 Harapan Pengunjung terhadap Tingkat Keinteraktifan Cyberwoman

Pada Gambar 11, 47\% responden menyatakan sangat tidak puas dengan tingkat keinteraktifan CyberWoman, sisanya menyatakan tidak puas (29\%), puas hanya sebesar 15\%, dan sangat puas sebesar 9\%. Responden menyatakan bahwa tingkat keinteraktifan CyberWoman tersebut sangat penting sebesar 50\%, penting sebesar 48\%, tidak penting sebesar $2 \%$, dan $0 \%$ yang menyatakan sangat tidak penting.

\section{Analisis Kesesuaian Kinerja Situs Portal dan Tingkat Harapan Pengunjung terhadap Informasi dan Layanan CyberWoman}

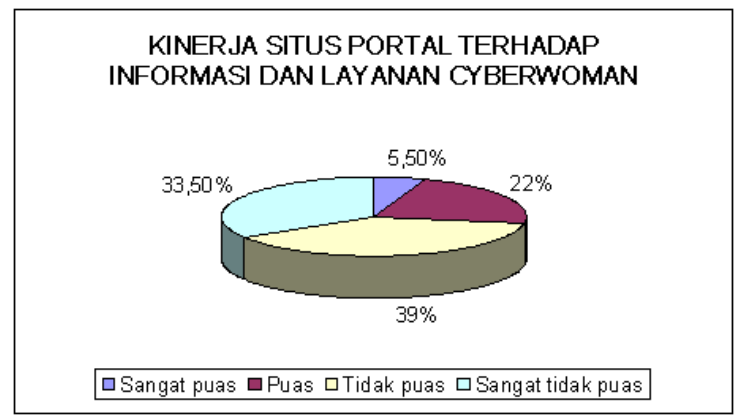

Gambar 13 Kinerja Situs Portal terhadap Informasi dan Layanan Cyberwoman

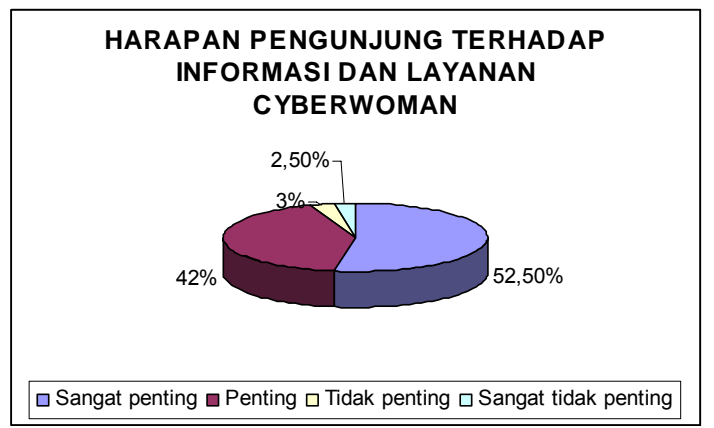

Gambar 14 Harapan Pengunjung terhadap Informasi dan Layanan Cyberwoman 
Gambar 13 menunjukkan bahwa 39\% responden tidak puas akan informasi dan layanan CyberWoman, 33,50\% responden lainnya bahkan menyatakan sangat tidak puas. Responden yang menyatakan puas hanya sebesar 22\% dan sisanya sebesar 5,50\% mengaku sangat puas. Harapan responden yang dapat dilihat pada Gambar 14 menyatakan bahwa informasi dan layanan CyberWoman sangat penting (52,50\%), penting (42\%), tidak penting (3\%), dan sangat tidak penting (2,50\%).

\section{Analisis Kesesuaian Kinerja Situs Portal dan Tingkat Harapan Pengunjung terhadap Promosi CyberWoman}

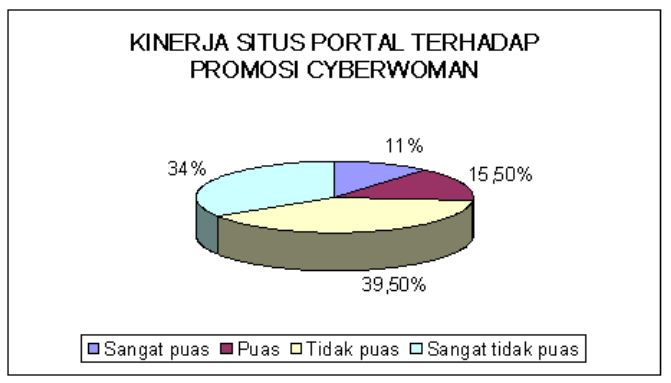

Gambar 15 Kinerja Situs Portal terhadap Promosi Cyberwoman

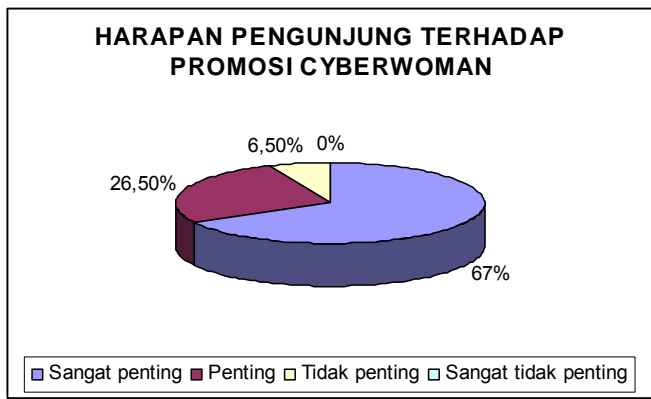

Gambar 16 Harapan Pengunjung terhadap Promosi Cyberwoman

Gambar 15 menunjukkan bahwa responden yang menyatakan tidak puas akan promosi CyberWoman sebesar 39,50\%, responden yang sangat tidak puas sebesar 34\%, kemudian, $15,50 \%$ responden menyatakan puas, dan sisanya $11 \%$ sangat puas. Pada gambar selanjutnya, yaitu Gambar 16 dapat kita lihat bahwa responden sangat mengharapkan promosi CyberWoman (67\%), penting (26,50\%), tidak penting (6,50\%), dan sangat tidak penting $(0 \%)$. 


\section{Analisis Urutan Sub-Content}

Tabel 2. Tabel Analisis Urutan

\begin{tabular}{|c|c|c|c|}
\hline No. 17 & No. 18 & No. 19 & No. 20 \\
\hline A & H & H & A \\
\hline G & I & L & B \\
\hline D & E & C & D \\
\hline B & A & K & K \\
\hline K & L & A & C \\
\hline C & J & J & G \\
\hline E & B & B & E \\
\hline F & K & I & J \\
\hline H & F & F & I \\
\hline J & C & G & L \\
\hline I & D & D & F \\
\hline L & G & E & H \\
\hline
\end{tabular}

Tabel 3 Tabel Keterangan Output Kuisioner

\begin{tabular}{|ll|}
\hline & \multicolumn{1}{c|}{ Keterangan : } \\
\hline A & Fashion (\& Fashion Consultation) \\
B & Beauty (\& Inner Beauty Consultation) \\
C & Health (\& Obgyn Consultation) \\
D & Career \\
E & Cooking \\
F & Mother and Baby \\
G & Love \\
H & Batita (\& Child Consultation) \\
I & Celebs and Kids \\
J & Smart Woman \\
K & Your Tips (\& Feng Shui Consultation) \\
L & Forum \\
\hline
\end{tabular}

Pada pertanyaan ke-17 ditanyakan tentang frekuensi kunjungan ke masingmasing subcontent CyberWoman. Tiga urutan teratas adalah Fashion (\& Fashion Consultation) sebesar 42\%, Love (26\%), dan Career (37\%). Tiga urutan terbawah adalah Forum (47\%), Celebs and Kids (49\%), dan Smart Woman (43\%). Pada pertanyaan ke-18 ditanyakan tentang ketertarikan terhadap tampilan masing-masing subcontent CyberWoman. Tiga urutan teratas adalah Batita (\& Child Consultation) sebesar 26\%, Celebs and Kids (24\%), dan Cooking (24,50\%). Tiga urutan terbawah adalah Love (30,50\%), Career $(27,50 \%)$, dan Health (\& Obgyn Consultation) sebesar 29,50\%. Pada pertanyaan ke-19 ditanyakan tentang keinteraktifan masing-masing subcontent 
CyberWoman. Tiga urutan teratas adalah Batita (\& Child Consultation) sebesar 20\%, Forum (25,50\%), dan Health (\& Obgyn Consultation) sebesar 24,50\% sedangkan tiga urutan terbawah adalah Cooking (34,50\%), Career (43\%), dan Love (37\%).

Pada pertanyaan ke-20, ditanyakan tentang manfaat informasi dan layanan yang disajikan oleh masing-masing sub-content CyberWoman. Tiga urutan teratas adalah Fashion (\& Fashion Consultation) sebesar 19,50\%, Beauty (\& Inner Beauty Consultation) sebesar 29\%, dan Career (18,50\%) sedangkan tiga urutan terbawah adalah Batita (\& Child Consultation) sebesar 28\%, Mother and Baby (23,50\%), dan Forum (27,50\%). Subcontent yang paling jarang dikunjungi adalah Forum. Menurut pendapat dari beberapa pengunjungnya, mereka enggan bergabung karena malas untuk melakukan proses registrasi yang dinilai terlalu rumit serta topik obrolan yang tidak bervariasi.

Sub-content yang paling tidak menarik adalah sub-content Love. Menurut pendapat dari beberapa pengunjungnya, sub-content ini jauh dari apa yang mereka harapkan. Padahal mereka sangat antusias ketika mengetahui akan keberadaan subcontent Love. Namun mereka menjadi kecewa ketika melihat sub-content ini terlalu biasa dan tidak lebih dari salinan rubrik majalah tentang percintaan. Sub-content yang paling tidak interaktif adalah Cooking. Menurut pendapat dari beberapa pengunjungnya, mereka memaklumi jika sub-content ini tidak interaktif karena jika dilihat dari judulnya saja, tidak mungkin dapat memasak bersama di dalam dunia maya.

\section{Analisis Kritik dan Saran Perbaikan CyberWoman di Masa Mendatang}

Ada beberapa kritik dan saran bagi masing-masing sub content CyberWoman yang merupakan hasil dari pengolahan kuisioner yang telah disebarkan, antara lain sebagai berikut.

Tabel 4 Analisis Kritik dan Saran

\begin{tabular}{|c|}
\hline Fashion (\& Fashion Consultation) \\
\hline $\begin{array}{ll}\text { - } & \text { Konsultasi fashion secara online dan dua arah } \\
\text { - } & \text { Fashion mode terbaru } \\
\text { - } & \text { Fashion mode dari berbagai budaya (Jepang, Amerika, Eropa, dll.) } \\
\text { - } & \text { Daftar tempat belanja (fashion) yang murah meriah serta petanya (link ke CyberMap) } \\
\text { - } & \text { Fashion mode-nya jangan terbatas pada wanita karir saja } \\
\text { - } & \text { Tampilkan kamus dress code agar tidak salah kostum dalam menghadiri suatu event }\end{array}$ \\
\hline Beauty (\& Inner Beauty Consultation) \\
\hline $\begin{array}{ll}\text { - } & \text { Konsultasi inner beauty tolong diadakan lagi secara online dan dua arah } \\
\text { - } & \text { Test make up virtual pada foto yang di-upload } \\
\text { - } & \text { Tampilkan info produk dan harga make-up terbaru yang sedang trend } \\
\text { - } & \text { Daftar nama salon, facial dan spa serta petanya (link ke CyberMap) } \\
\text { - } & \text { Tampilkan tips - tips dandanan untuk berbagai occasion } \\
\text { - } & \text { Tampilkan tips - tips seputar rambut keriting (model dan perawatannya) }\end{array}$ \\
\hline
\end{tabular}




\section{Health (\& Obgyn Consultation)}

- $\quad$ Dokter online penyakit - penyakit khusus wanita

- Konsultasi obgyn secara online dan dua arah

- Tampilkan artikel penyakit - penyakit baru yang belum diketahui (cara menghindari dan menanggulangi)

- Tampilkan sex education dilihat dari sudut pandang wanita

- Tampilkan daftar kandungan kalori, lemak dan protein makanan untuk wanita yang sedang diet

- Informasi kesehatan hendaknya disesuaikan dengan penyakit yang sedang mewabah pada musim itu

- Informasi yang ada selama ini kurang bermanfaat

\section{Career}

- $\quad$ Tampilkan tips - tips untuk memulai usaha sendiri

- Tampilkan tips - tips meniti karir bagi fresh graduate

\section{Cooking}

- $\quad$ Kontes kirim resep masakan dan tips seputar dapur, pemenang ditentukan lewat vote SMS pengunjung lainnya

- $\quad$ Perbanyak resep dari beragam budaya mancanegara

- Perbanyak resep seputar desert

- $\quad$ Perbanyak tips - tips seputar dapur

\section{Mother and Baby}

- $\quad$ Lomba tips seputar ibu dan bayi. Pemenang ditentukan lewat vote SMS pengunjung lainnya Love

- $\quad$ Ramalan cinta online

- $\quad$ Love test diri sendiri - online

- Adakan lomba puisi cinta yang pemenangnya ditentukan lewat vote SMS dari pengunjung lainnya

- Tampilkan artikel untuk wanita yang belum memiliki pasangan

Batita (\& Child Consultation)

- $\quad$ Konsultasi child secara online dan dua arah

- Kualitas foto kontes batita harap ditingkatkan

\section{Celebs and Kids}

- Gaya bahasa dibuat seperti infotainment saja agar lebih menarik

- Kualitas foto harap ditingkatkan

- $\quad$ Smart woman yang ditampilkan kurang "smart"

- Hampir tidak pernah di-update

\section{Your Tips (\& Feng Shui Consultation)}

- $\quad$ Konsultasi Feng Shui secara online dan dua arah

- $\quad$ Sebaiknya semua tips - tips yang ada di CyberWoman disatukan di sini

- $\quad$ Perbanyak tips

- $\quad$ Tips - tips yang kurang bermanfaat harap disortir

- Jangan menampilkan tips - tips yang sudah menjadi rahasia umum

\section{Forum}

- $\quad$ Registrasi dipermudah agar semakin banyak peminat

- Buat tampilan seperti messenger agar lebih menarik dan online dua arah

- Topik obrolan diperbanyak

- Buat acara gathering antar sesama pengguna forum 


\section{Analisis SWOT}

SWOT adalah singkatan dari kekuatan (Strengths) dan kelemahan (Weaknesses) intern perusahaan serta peluang (Opportunities) dan ancaman (Threats). Analisis SWOT merupakan cara sistematis untuk mengidentifikasi faktor tersebut dan strategi yang menggambarkan kecocokan paling baik diantara mereka. Analisis SWOT CyberWoman adalah sebagai berikut. Pertama, Strengths: Variasi 12 (dua belas) sub-content CyberWoman sudah melengkapi kebutuhan para wanita; Informasi yang disajikan selalu up-to-date. Kedua, Weaknesses: Kurangnya promosi sehingga belum banyak yang mengetahui keberadaan CyberWoman; Tampilan (layout design) yang monoton sehingga membuat pengunjung cepat bosan; Tingkat interaktifitas CyberWoman yang masih tergolong rendah; Pembataan segmentasi pasar hanya pada wanita karir berusia antara 25 - 49 tahun. Ketiga, Opportunities: Era teknologi informasi yang memberi peluang bagi Internet untuk tumbuh dan berkembang; Menjamurnya website, khususnya situs portal di Indonesia; Akses Internet yang dapat dilakukan oleh siapapun, kapanpun, dan dimanapun; Jumlah pesaing content atau situs portal khusus wanita masih relatif sedikit jumlahnya; Jumlah pendatang baru yang belum terlihat secara signifikan; Semakin banyak wanita yang berkarir; Meningkatnya jumlah pengunjung menjadi peluang untuk menarik minatnya menjadi pelanggan CBN; Banyaknya pemasok yang membuat CyberWoman menjadi semakin lengkap dan sempurna. Keempat, Threats: Belum semua wanita mampu mengakses Internet; Belum semua wanita memiliki fasilitas untuk mengakses Internet; Belum semua wanita mengetahui keberadaan CyberWoman; Banyaknya produk pengganti (substitusi) yang lebih dikenal oleh para wanita dibandingkan mengakses Internet; Banyaknya hacker (cyber crime) yang menyebabkan para wanita enggan untuk mengakses Internet

\section{IFAS}

Tabel 5 IFAS

\begin{tabular}{|c|c|c|c|}
\hline $\begin{array}{l}\text { Faktor - faktor } \\
\text { Strategi Internal }\end{array}$ & Bobot & Rating & $\begin{array}{c}\text { Bobot } \\
\text { x Rating }\end{array}$ \\
\hline \multicolumn{4}{|l|}{ Kekuatan : } \\
\hline - Variasi 12 (dua belas) sub content sudah melengkapi kebutuhan para wanita & 0,20 & 4 & 0,80 \\
\hline - Informasi yang disajikan selalu $u p$-to-date & 0,20 & 3 & 0,60 \\
\hline \multicolumn{4}{|l|}{ Kelemahan: } \\
\hline $\begin{array}{l}\text { - Kurangnya promosi sehingga belum banyak yang mengetahui keberadaan } \\
\text { CyberWoman }\end{array}$ & 0,20 & 2 & 0,40 \\
\hline $\begin{array}{l}\text { - Tampilan (loyout design) yang monoton sehingga membuat pengunjung } \\
\text { cepat bosan }\end{array}$ & 0,15 & 2 & 0,30 \\
\hline - Tingkat interaktifitas CyberWoman yang masih relatif rendah & 0,15 & 2 & 0,30 \\
\hline $\begin{array}{l}\text { - Penbatasan segmentasi pasar hanya pada wanita karir berusia antara } 25 \text { - } 49 \\
\text { tahun }\end{array}$ & 0,10 & 1 & 0,10 \\
\hline Total & 1,00 & & 2,50 \\
\hline
\end{tabular}




\section{EFAS}

Tabel 6 EFAS

\begin{tabular}{|c|c|c|c|}
\hline $\begin{array}{c}\text { Faktor - faktor } \\
\text { Strategi Eksternal }\end{array}$ & Bobot & Rating & $\begin{array}{l}\text { Bobot } \\
\text { x Rating }\end{array}$ \\
\hline \multicolumn{4}{|l|}{ Peluang : } \\
\hline $\begin{array}{l}\text { - Era teknologi informasi yang memberi peluang bagi intemet unituk } \\
\text { berkembang }\end{array}$ & 0,15 & 4 & 0,60 \\
\hline - Menjamurnya webs ite, khususnya situs portal & 0,10 & 4 & 0,40 \\
\hline $\begin{array}{l}\text { - Akses internet yang dapat dilakukan oleh siapapun, kapanpun, dan di } \\
\text { manapun }\end{array}$ & 0,10 & 4 & 0,40 \\
\hline $\begin{array}{l}\text { - Jumlah pesaing situs portal maupun content situs portal yang ditujukan } \\
\text { khusus bagi wanita masih relatif sedikit jumlahnya }\end{array}$ & 0,07 & 4 & 0,28 \\
\hline - Jumlah pendatang baru vang belum terlihat secara signifikan & 0,07 & 4 & 0,28 \\
\hline - Semakin banyak wanita yang berkarir & 0,06 & 3 & 0,18 \\
\hline $\begin{array}{l}\text { - Meningkatnya juniah pengunjung menjadi peluang untuk menarik minatnya } \\
\text { menjadi pelanggan CBN }\end{array}$ & 0,05 & 3 & 0,15 \\
\hline $\begin{array}{l}\text { - Banyaknya pemasok yang memudahkan untuk menjadikan Cyber'woman } \\
\text { menjadi semakin lengkap dan sempurna }\end{array}$ & 0,04 & 3 & 0,12 \\
\hline \multicolumn{4}{|l|}{ Ancaman : } \\
\hline - Belum semua wanita mampu mengakses internet. & 0,10 & 2 & 0,20 \\
\hline - Belum semua wanita memiliki fasilitas untuk mengakses internet. & 0,08 & 2 & 0,16 \\
\hline - Belum semua wanita mengetahui keberadaan CvberWoman & 0,08 & 2 & 0,16 \\
\hline - Banyaknya produk pengganti (substitusi) yang lebih dikenal oleh para wanita & 0,06 & 1 & 0,06 \\
\hline \multirow{2}{*}{$\begin{array}{l}\text { - Meningkatnya hacker (cyber crime) yang menyebabkan wanita enggan untuk } \\
\text { mengakses internet. }\end{array}$} & 0,04 & 1 & 0,04 \\
\hline & 1,00 & & 3,03 \\
\hline
\end{tabular}




\section{Diagram SWOT}

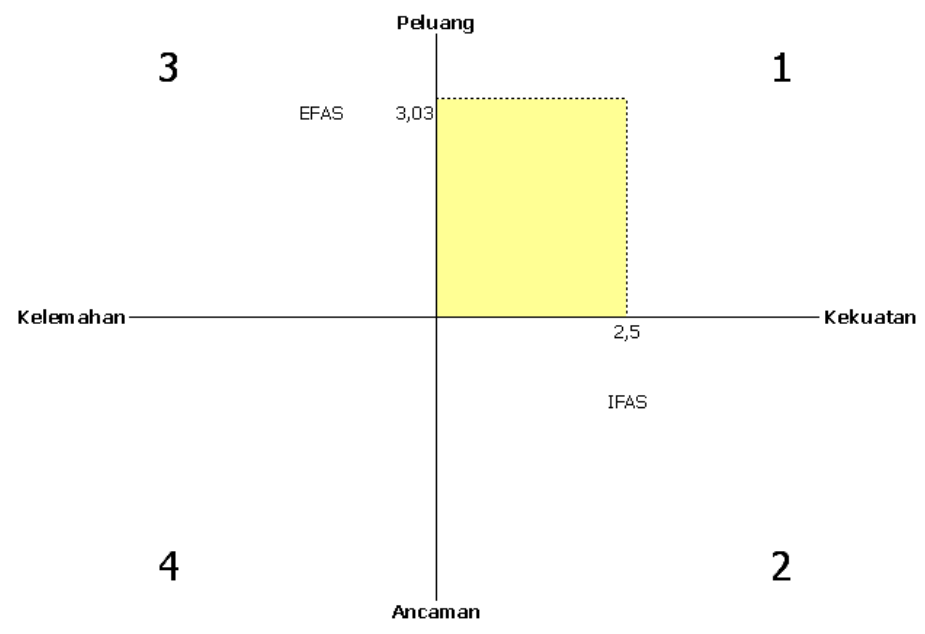

Gambar 17 Diagram SWOT

Dari Diagram SWOT di atas, maka dapat dilihat bahwa perusahaan termasuk pada Kuadran 1. Hal ini berarti bahwa perusahaan tersebut memiliki situasi yang sangat menguntungkan. Perusahaan tersebut memiliki peluang dan kekuatan, sehingga dapat memanfaatkan peluang yang ada. Strategi yang harus diterapkan dalam kondisi ini adalah strategi yang mendukung kebijakan pertumbuhan yang agresif.

\section{Matriks Internal Eksternal (IE)}

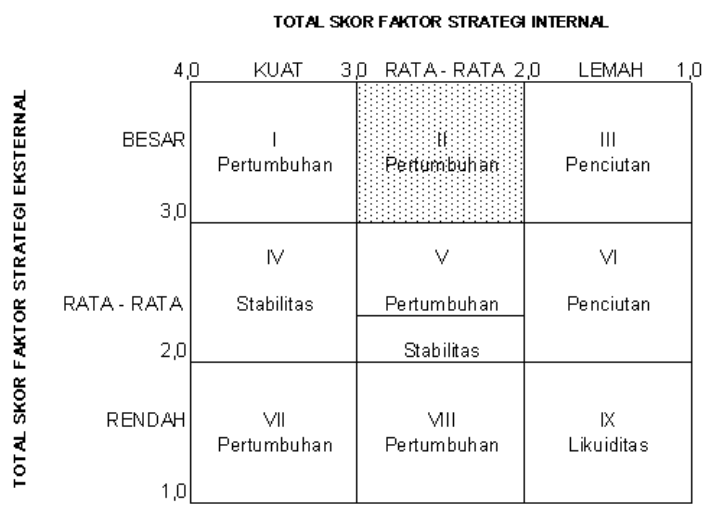

Gambar 18 Matriks Internal Eksternal (IE)

Dari Matriks IE tersebut, dapat dilihat bahwa faktor strategi internal dan eksternal perusahaan berada dalam tahap pertumbuhan dan perusahaan harus menggunakan strategi konsentrasi melalui integrasi horizontal. 


\section{Diagram Cartesius}

Tabel 8 Perhitungan Rata-rata Kinerja Situs Portal dan Harapan Pengunjung Cyberwoman

\begin{tabular}{|c|c|c|c|c|c|c|}
\hline No & Indikator & $\begin{array}{c}\text { Kinerja } \\
\text { Situs } \\
\text { Portal } \\
(\mathrm{X}) \\
\end{array}$ & $\begin{array}{c}\text { Harapan } \\
\text { Pengunjung } \\
\text { (Y) }\end{array}$ & $\bar{x}$ & $\bar{Y}$ & Tki \\
\hline 1 & Tampilan Cyberivoman & 437 & 716 & 2,19 & 358 & $61,03 \%$ \\
\hline 2 & Bandwith CBN & 620 & 736 & 3,1 & 368 & $84,24 \%$ \\
\hline 3 & Tingkat inter aktifitas CyberWoman & 372 & 696 & 1,86 & 3,48 & $53,45 \%$ \\
\hline 4 & Informasi dan layanan Cyberwoman & 332 & 689 & 1,66 & 3,45 & $48,19 \%$ \\
\hline 5 & Promosi Cyberwoman & 407 & 721 & 2,04 & 361 & $56,45 \%$ \\
\hline \multicolumn{4}{|c|}{ Rata } & 2,17 & 3,56 & $60,93 \%$ \\
\hline
\end{tabular}

Dari Tabel 8 dapat dilihat bahwa Tki (tingkat kesesuaian responden) di bawah nilai rata - rata Tki (tingkat kesesuaian responden) harus mendapatkan perhatian khusus dari CBN.

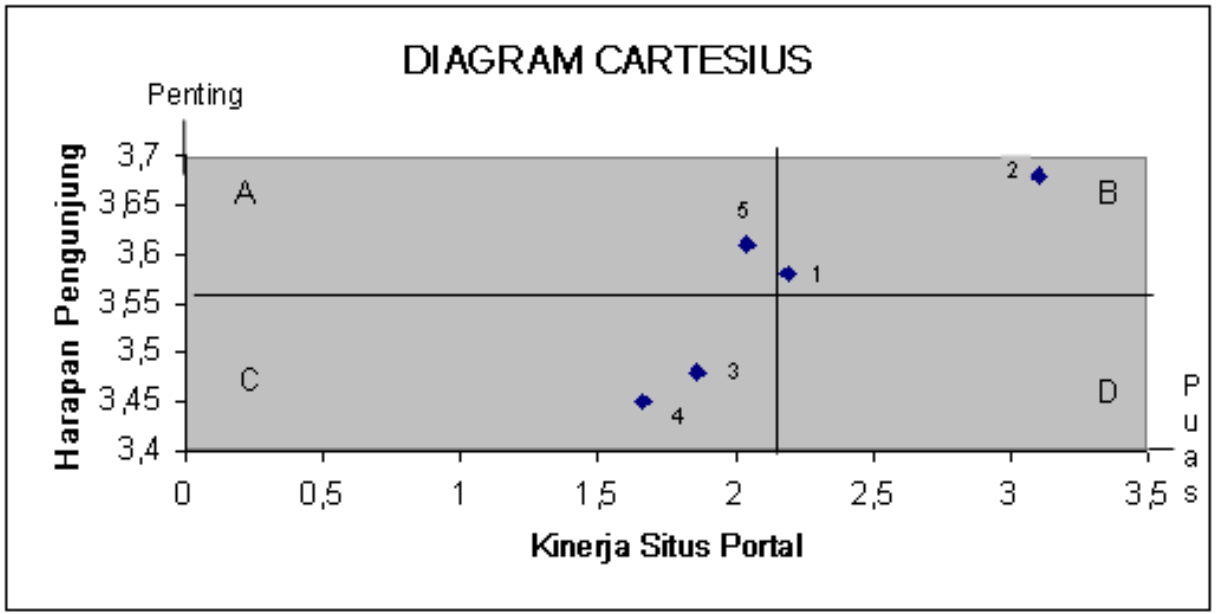

Gambar 19 Diagram Cartesius

Dari hasil perhitungan Tabel 8 Perhitungan rata - rata kinerja perusahaan dan harapan pengunjung CyberWoman, diperoleh Gambar 19 Diagram Cartesius. Dalam gambar itu terlihat bahwa diagram terbagi menjadi empat bagian. Hasil pengukuran faktor kinerja situs portal dan harapan pengunjung tersebut dapat menemukan titik berat yang harus diperbaiki oleh perusahaan. Diagram Cartesius tersebut dijelaskan dalam uraian sebagai berikut. Pertama, Kuadran A menunjukkan bahwa faktor yang berada pada Kuadran A perlu diprioritaskan oleh perusahaan. Hal itu terjadi karena keberadaan faktor harapan dinilai sangat penting oleh pengunjung sedangkan tingkat kinerjanya masih belum memuaskan. Faktor yang termasuk dalam Kuadran A adalah Promosi CyberWoman. Kedua, Kuadran B menunjukkan bahwa faktor yang berada pada kuadran 
B perlu dipertahankan karena pada umumnya tingkat kinerjanya telah sesuai dengan harapan pengunjung. Faktor yang termasuk dalam kuadran B adalah Tampilan (layout design) CyberWoman dan Bandwith CBN. Ketiga, Kuadran C menunjukkan bahwa faktor yang berada pada kuadran $\mathrm{C}$ dinilai masih kurang penting bagi pengunjung sedangkan tingkat kinerjanya biasa. Faktor yang termasuk pada Kuadran $\mathrm{C}$ adalah tingkat interaktifitas CyberWoman dan informasi dan layanan CyberWoman. Keempat, Kuadran D menunjukkan bahwa faktor yang berada pada Kuadran D dinilai berlebihan dalam tingkat kinerjanya. Hal itu terutama karena pengunjung menganggap tidak terlalu penting terhadap adanya faktor tersebut. Akan tetapi, pelaksanaannya dilakukan dengan sangat baik oleh perusahaan. Tidak ada faktor yang termasuk dalam Kuadran D.

\section{PENUTUP}

Beberapa simpulan yang diperoleh untuk menjawab identifikasi masalah adalah sebagai berikut. Pertama, dari hasil penelitian diperoleh informasi sebagai berikut: subcontent yang paling sering dikunjungi adalah Fashion (\& Fashion Consultation), subcontent yang paling menarik menurut para pengunjung CyberWoman adalah Batita (\& Child Consultation), sub-content yang paling interaktif adalah Batita (\& Child Consultation), sub-content yang paling bermanfaat adalah Fashion (\& Fashion Consultation). Jadi, sub-content Fashion (\& Fashion Consultation) paling sering dikunjungi dan juga paling bermanfaat menurut para pengunjungnya. Kedua, sub-content Batita (\& Child Consultation) adalah sub-content yang paling menarik dan interaktif. Namun, sub-content ini paling tidak bermanfaat menurut para pengunjungnya. Maka subcontent yang lain harus dibuat sebaik sub-content Batita (\& Child Consultation), khususnya dalam memperbaiki tampilan (layout design) serta tingkat interaktivitasnya. Menurut pendapat dari beberapa pengunjungnya, sub-content ini tidak bermanfaat karena sebagian besar hanya menampilkan lomba foto batita. Jadi, bagi yang tidak ikut lomba foto tersebut tidak dapat merasakan manfaatnya.

Ketiga, diagram SWOT menunjukkan bahwa CBN memiliki peluang dan kekuatan yang dapat dimanfaatkan. Strategi yang mendukung adalah strategi kebijakan pertumbuhan yang agresif. Keempat, matriks Internal Eksternal (IE) menunjukkan bahwa perusahaan berada dalam pertumbuhan. Perusahaan harus menerapkan strategi konsentrasi melalui integrasi horizontal. Kelima, Diagram Cartesius menunjukkan bahwa promosi CyberWoman harus diprioritaskan, tampilan CyberWoman dan bandwith CBN harus dipertahankan, namun tingkat interaktivitas dan informasi serta layanan yang disajikan oleh CyberWoman dinilai biasa.

Beberapa saran yang mungkin dapat menjadi konsep perbaikan guna membantu perkembangan PT Cyberindo Aditama di masa yang akan datang, khususnya dalam mengelola strategi manajemen CyberWoman adalah sebagai berikut. Pertama, subcontent Fashion (\& Fashion Consultation) perlu dipertahankan bahkan ditingkatkan 
kualitasnya. Kedua, topik obrolan dalam sub-content forum harus lebih ditingkatkan serta proses registrasi dipermudah dan dipersingkat agar lebih banyak yang mau bergabung di dalamnya. Tampilannya akan lebih menarik jika dibuat seperti Messenger. Ketiga, subcontent Love harus dibuat lebih menarik dan lebih interaktif agar pengunjung tidak merasa dikecewakan. Keempat, walaupun agak sulit untuk meningkatkan keinteraktivan sub-content Cooking, namun CBN masih dapat mengadakan lomba seperti yang dilakukan pada sub-content Batita.

Kelima, peningkatan promosi agar CyberWoman dapat lebih dikenal oleh masyarakat, khususnya wanita Indonesia. Keenam, selebaran segmentasi pasar CyberWoman sehingga semua wanita merasa nyaman ketika mengunjungi CyberWoman. Ketujuh, pembaharuan versioning situs portal CBN agar tidak ketinggalan dan kalah bersaing dengan perusahaan (Internet Service Provider) ISP sejenis. Kedelapan, pembaharuan tampilan (layout design) pada setiap sub-content CyberWoman agar tidak terlihat monoton sehingga membuat para pengunjung tidak tertarik dan cepat bosan walaupun Informasi dan layanan yang diberikan sudah cukup bagus.

\section{DAFTAR PUSTAKA}

Amor, Daniel. 2004. E-Business (Revolution). New Jersey: Prentice Hall.

Awad, Elias M. 2002. Electronic Commerce: From Vision to Fulfillment. Prentice Hall, New Jersey.

Chaffey, Dave. 2000. Internet Marketing. Wiltshire: Prentice Hall.

Collins, Heidi. 2001. Corporate Portals: Revolutionizing Information Access to Increase Productivity and Drive the Bottom Line. New York: Amacom.

Coupey, Eloise. 2002. Marketing and The Internet Conceptual Foundation. New Jersey: Prentice Hall.

Diana, Anastasia. 2001. Mengenal e-Business. Yogyakarta: Andi.

Forrest, Ed. 2001. Internet Marketing Research Resources an Technic. Sidney: McGrawHill.

Hadi, Sunaryo. 2001. "Website Review." Diakses 18 Mei 2005 dari http://www.coldfusion.web.id/index.cfm/fuseaction/section.read/id/1, http://cyberwoman.cbn.net.id,

Kalakota, Ravi. 2001. E-Business 2.0: Roadmap for Success. Canada: Addison-Wesley. 
Kim, Amy Jo. 2001. Community Building on the Web: Secret Strategies for Successful Online Communities. Berkeley: Peachpit Press.

Mougayar, et al. 2001. The Business and Intranets: A Manager's Guide to Key Terms and Concepts. USA: Harvard Business School.

Nakano, Russell. 2002. Web Content Management: A Collaborative Approach. Canada: Addison Wesley.

Neuman, W. Lawrence. 2000. Social Research Methods: Qualitative and Quantitative Approaches. Needham Heights: Allyn and Bacon.

Rangkuti, Freddy. 2003. Analisis SWOT Teknik Membedah Kasus Bisnis. Jakarta: Gramedia Pustaka Utama.

Resha. 2005. "Content Management System: Mengenal Content Management System.” SDA Asia Magazine, Maret 2005 (Edisi 3), 28 - 30.

Rickyanto, Isak. 2003. "Panduan Pengenalan dan Memilih Open Source Content Management System Berbasis PHP.” Diakses 18 Mei 2005 dari http://diskusiweb.com/php/article_opensourcecmsdgphp.html,

Robertson, James. “So, What Is A Content Management System?” Diakses 18 Mei 2005 dari http://www.steptwo.com.au/papers/kmc_what/,

Saladin, Djaslim. 2004. Manajemen Pemasaran. Edisi 3. Bandung: CV Linda Karya.

Saleh, Hilda. 2005. "Content Management System: Pertimbangan Penting Saat Memilih Solusi CMS.” SDA Asia Magazine, Maret 2005 (Edisi 3), 38 - 40.

Sekaran, Uma. 2003. Research Methods for Business: A Skill Building Approach. United States of America: John Wiley and Sons, Inc.

Turban, Efraim. 2002. Electronic Commerce: A Managerial Perspective. New Jersey: Pearson Education.

Walker, Boyd, Mullins and Larreche. 2005. Marketing Strategy Decision Focus Approach. Edisi Keempat. Boston: McGraw Hill.

Wheelen, Thomas and J. David. Hunger. 2004. Strategic Management and Business Policy. New Jersey: Prentice Hall.

Widodo, Teguh. 2005. "Content Management System: Mengungkap Seluk Beluk Content Management System.” SDA Asia Magazine, Maret 2005 (Edisi 3), 32 - 37. 